A constant increase in occurrence of neoplasms is observed; hence new methods of therapy are being intensively researched. One of the methods of antineoplastic treatment is molecular targeted therapy, which aims to influence individual processes occurring in cells. Using this type of medications is associated with unwanted effects resulting from the treatment. Liver damage is a major adverse effect diagnosed during targeted therapy. Drug-induced liver damage can occur as necrosis of hepatocytes, cholestatic liver damage and cirrhosis. Hepatotoxicity is evaluated on the basis of International Consensus Criteria. Susceptibility of the liver to injury is connected not only with toxicity of the used medications but also with metastasis, coexistence of viral infections or other chronic diseases as well as the patient's age. It has been proven that in most cases the liver injury is caused by treatment with multikinase inhibitors, in particular tyrosine kinase inhibitors. The Food and Drug Administration (FDA) ordered the inclusion of additional labels - so-called "black box warnings" - indicating increased risk of liver injury when treating with pazopanib, sunitinib, lapatinib and regorafenib. A meta-analysis published in 2013 showed that treating neoplastic patients with tyrosine kinase inhibitors can increase the risk of drug-induced liver damage at least twofold. Below the mechanisms of drug-induced liver injury and hepatotoxic effects of molecular targeted therapy are described.

Key words: liver injury, molecular targeted therapy.

Contemp Oncol (Pozn) 2015; 19 (2): 87-92 DOI: $10.5114 /$ wo.2014.43495

\section{Hepatotoxicity of molecular targeted therapy}

\author{
Bożenna Karczmarek-Borowskaํ, Agata Sałek-Zañ ${ }^{2}$
}

${ }^{1}$ Department of Oncology, Faculty of Medicine, University of Rzeszow, Rzeszow, Poland ${ }^{2}$ Department of Clinical Oncology, Podkarpacie Oncology Center, Rzeszow, Poland

\section{Introduction}

The occurrence of neoplastic diseases in Poland increases each year. 83470 new cases were diagnosed in 1990, compared to 140654 in 2010. In 1990, 72914 people died of malignant neoplasms while 92611 died in 2010 $[1,2]$.

One of the main methods of treating neoplastic diseases is by the use of chemotherapy, but recently, a significant role is played by molecularly directed drugs. Several types of organ damage, including liver damage, are the result of antineoplastic treatment. In the case of patients with neoplastic disease the liver damage is a result of not only cytostatics and biologically active drugs but also coexisting viral infections, primary liver diseases or other chronic illnesses [3]. Metastatic changes occurring in the liver also affect its proper function. Deficits in liver function result from a decrease in volume of normal hepatocytes, compression and decrease of the lumen of the intraand extrahepatic biliary system or portal vein thrombosis [4]. Patient's age is also an essential factor determining susceptibility to drug-induced hepatotoxicity [5]. Liver damage caused by medications or other non-infectious factors is called hepatotoxicity [6].

\section{Mechanics and symptoms of liver damage}

The liver is an organ responsible for lipid management, metabolism of carbohydrates, proteins, heme, bilirubin, storage of vitamins $A, B_{12}$, and $D$, iron binding with ferritin, and production and excretion of bile. Moreover, it serves immunologic and detoxifying purposes [7]. One of the methods to evaluate liver efficiency is to measure the activity of 4 enzymes. Aspartate transaminase (ASPAT) and alanine transaminase (ALAT) are intracellular enzymes; however, ALAT is more specific to liver cells. ASPAT also occurs in heart muscle cells, skeletal muscles and erythrocytes. Alkaline phosphatase occurs in the epithelium of intrahepatic bile ducts and takes part in substance transport through the cell membrane. An increase in alkaline phosphatase content may suggest that intrahepatic and extrahepatic bile ducts are obstructed or liver cells are damaged but to a lesser extent. Gamma-glutamyltransferase (GGTP) is present in several tissues but the greatest amount of it is in liver cells. Isoenzymes of alkaline phosphatase and ASPAT may occur in many other tissues; however, an increase in GGTP and ALAT may indicate liver damage. The level of serum bilirubin is proportional to its uptake and conversion by hepatocytes. An increase of bilirubin gives grounds for diagnosing cholestasis. In people with neoplastic disease, cholestasis can be a result of damage to intrahepatic bile ducts [4]. Elevated levels of transaminases alone do not fully reflect liver disorders. Other tests that allow one to assess liver function are the antipyrine test, galactose elimination ability test, and bromsulphthalein clearance evaluation. However, they are difficult to apply in everyday practice. The Child-Pugh scale is used to evaluate liver efficiency for transplant qualification and determining appropriate drug doses but it is not always reliable [8]. Liver synthesizing abilities can 
be determined by the measurement of the albumin level or prothrombin time. Albumin is a protein made by the liver. It is responsible for transporting several substances including medicines, and maintaining oncotic blood pressure. Because the liver includes significant reserve of albumins, a decrease of the content of these proteins tends to be associated with chronic liver diseases rather than with its acute injury. In turn, prothrombin, a protein that takes part in the blood-clotting process, is synthesized by hepatocytes. Its content is determined by measurement of the prothrombin time. Prothrombin time abnormalities may indicate that the synthesizing function of the liver is impaired [4].

Taking into consideration increased activity of ALAT and alkaline phosphatase, drug-induced liver damage can be divided into 3 groups: liver cell damage, cholestatic damage, and drug-induced liver damage [9]. In spite of elevated values of the mentioned enzymes, many patients do not feel any ailments and do not have visible functional disorders of other organs [4].

An essential task of the liver is to transform exogenous substances, including medicines, into hygrophilous compounds and excrete them from the body with bile and urine. These compounds are oxidized with the help of cytochrome P450, then undergo a conjugation process [10]. Cytochrome P450 is a group of about 30 types of enzymes that include heme in their structure; they are present in the endoplasmic reticulum of hepatocytes. They are mainly responsible for drug metabolism. They are described as families numbered from 1 to 4 . It is believed that $90 \%$ of drug oxidation processes occur with the participation of types CYP1A2, 2C9, 2C19, 2D6, 2E1, 3A4/5. Cytochromes CYP3A4 and CYP2D6 have the most significant role in drug metabolism [11]. During these transformations in liver cells, reactive metabolites can arise besides neutral products, which can harm hepatocytes [10]. Many factors have an influence on drug metabolism by CYP3A4, including treatment with alternative medicine preparations, smoking, alcohol consumption, and obesity. Presence of hepatotropic viruses also increases the risk of complications during chemotherapy. It is proven that coexistence of hepatitis B virus infection can lead to fulminant hepatic necrosis. The group of people who are susceptible to toxic liver injury also includes those who have undergone allogenic bone marrow transplantation and those with hepatic veno-occlusive disease or hepatic sinusoidal obstruction syndrome. The symptoms occur in the form of hyperbilirubinemia, hepatomegaly and fluid retention. Tumor cells influence metabolic functions of the liver as well. They produce a number of factors that stimulate, among others, cytokines such as interleukin-6 or tumor necrosis factor $\alpha$. Their activity is indicated by the increase of inflammatory markers such as C-reactive protein (CRP), as well as fever. It is proven that presence of an inflammatory response reduces activity of CYP3A4 in hepatocytes. Therefore, inflammation has an influence on activity of CYP3A4 and drug metabolism [4].

Hepatocyte necrosis is a typical complication of drug toxicity. Less often it proceeds in the form of damage to endothelial cells, epithelium of small bile ducts or Kupffer cells. Liver cell damage can be of chemical type or immuno- logic hypersensitivity type [12]. Another classification describes damage of hepatocytes as direct or indirect. Direct damage develops by administering a single, relatively high dose of a drug, or accumulation of doses. This mechanism is repeatable and predictable [10]. It is caused by a toxic metabolite of the drug [9]. In turn, indirect drug-induced liver damage (idiosyncrasy) arises by reaction of the drug metabolite with an enzyme (immunological idiosyncrasy) or as a result of metabolic hypersensitivity to the drug (metabolic idiosyncrasy). These mechanisms are generally unpredictable, rarely repeatable and often independent of the dose [10]. There is a temporal separation between the drug administration and the occurrence of the symptoms. They are more often evoked by the drugs rather than their metabolites [9]. Both of these mechanisms can appear at the same time [10]. Causes might include genetic predisposition, age, sex, coexisting diseases, use of other drugs or stimulants, body condition, hormonal imbalance, or pregnancy $[9,10]$. Pregnancy, use of stimulants, and malnutrition can increase susceptibility to toxic effects of drugs. Symptoms of drug-induced injury of hepatocytes are stomachache, vomiting, hunger disorders, and jaundice. It is estimated that from 3\% to $10 \%$ of cases of drug-induced liver damage develop into acute liver failure. The primary response is to discontinue the drug.

Drug-induced liver injury can proceed in an acute manner, where activity of the aminotransferases is very high, in the range of 500-20 $000 \mathrm{U} / \mathrm{l}$, but after discontinuation of the drug it normalizes quite quickly. However, the value of aminotransferases might be not a sufficient indicator when assessing toxicity because a decrease of their values can also reflect necrosis of the hepatocytes. When the drug-induced liver damage proceeds chronically or if the increase of aminotransferases is moderate, in the range of 120-500 U/l, then usually these levels may reflect severity of the disease. Chronic disease predisposes to cirrhosis. One rarely sees the form of fulminant (hyperacute) drug-induced liver damage, which could progress to acute liver failure and lead to death [9].

Cholestatic liver damage is one of the types of drug-induced liver damage (Table 1) [10]. It can occur in a mild, noninflammatory form without hepatocyte injury, but also an inflammatory form, with hepatocyte injury [9]. Jaundice lasting over 6 months or elevated markers of cholestasis lasting over 12 months is consistent with permanent damage of bile ducts.

Drug toxicity can also lead to cirrhosis. Concentric narrowing of the lobular veins as a result of connective tissue fiber overgrowth is called hepatic veno-occlusive disease. Intrahepatic blood reservoirs, occurring most frequently within lobules, probably caused by damage of the sinus vessel endothelium, are called peliosis hepatis. When focal nodular hyperplasia is diagnosed, it is associated with pseudo-cirrhotic regeneration [10]. Drug-induced liver damage can be a cause of hepatic vein thrombosis, chronic hepatitis, nonalcoholic hepatic lipidosis with inflammatory reaction as well as liver granulomas and tumors [9]. Drug-induced liver damage is assessed on the basis of International Consensus Criteria [13]. 
Table 1. Cholestatic liver injury

$\begin{array}{lll}\begin{array}{l}\text { Type } \\ \text { Large droplet steatosis }\end{array} & \begin{array}{l}\text { Pathogenesis } \\ \text { fatty acid transformation disorder, disorder of fatty } \\ \text { acid transport between hepatocytes and blood }\end{array} & \begin{array}{l}\text { Effect } \\ \text { hepatocyte necrosis, inflammation, } \\ \text { acute liver failure }\end{array} \\ \text { Hepatocellular cholestasis } & \begin{array}{l}\text { disorder of production and intracanalicular } \\ \text { secretion of bile caused by inflammatory process } \\ \text { in bile ducts }\end{array} & \begin{array}{l}\text { epithelial damage and swelling, intralobular and } \\ \text { extralobular bile duct obstruction, impaired bile flow } \\ \text { in extrahepatic bile ducts }\end{array} \\ \text { Ischemic cholangitis } & \text { intra-arterial administration of cytostatic drugs } & \text { ischemic cholangitis }\end{array}$

Drug-induced liver injury is regarded when 3 of the criteria are satisfied, or when the first 2 of them are satisfied and the result of the provocative trial is positive. It is believed that liver biopsy should be performed if there is no improvement in liver function in spite of discontinuation of the drug, when the cause of damage cannot be determined, as well as when corticosteroid treatment or liver transplantation is considered [9]. The liver metabolizes the majority of drugs used in treatment of neoplastic diseases, inactivating them or transforming them into active products. In the case of liver insufficiency they can cause toxic effects or their efficacy can be limited [4].

\section{Mechanism of action of molecular targeted therapy}

More precise understanding of the processes occurring inside of the neoplastic cells led to the emergence of new possibilities of treatment. Currently, monoclonal antibodies (MoAb), epidermal growth factor receptor inhibitors, tyrosine kinase inhibitors (TKI), inhibitors that influence individual elements of the mTOR pathway and inhibitors of growth factors are in use. Most of these are able to in fluence many sites of action. The mechanism of action of monoclonal antibodies consists in modulation of the immune system, disruption of the interaction between a receptor and a ligand, stimulation of ligand-dependent cell-mediated cytotoxicity (antibody-dependent cellular cytotoxicity - ADCC), or complement-associated stimulation of cytotoxicity (complement-mediated cytotoxicity - CMC) [14]. The group of receptor kinases includes the family of epidermal growth factor receptors. The family consists of: EGFR (erbB1), HER2/neu (erbB2), HER3 (erbB3), and HER4 (erbB4). They are trans-membranous proteins connected together. In this group, receptor HER3 does not have an intracellular tyrosine kinase domain and receptor HER2 does not bind with ligands extracellularly. Stimulation of EGFR and HER2 activates pathways of intracellular signal transfer such as the protein kinase pathway activated by mitogen (MAPK), or the kinase pathway PI3/Akt/mTOR. It leads to stimulation of cell growth, differentiation, mobility and adhesion. One quite well-known site of action for targeted drugs is the epidermal growth factor receptor (EGFR). It has an extracellular part which is connected with a ligand as well as an intracellular domain connected with tyrosine kinase [15]. It is proven that all tyrosine kinases are able to evoke hepatotoxicity [16]. Both elements associated and not associated with the cell membrane could be sites of action for molecular protein kinases [15]. Among tyrosine kinases, receptor and non-receptor groups can be distin- guished. The group of receptor kinases transfers the signal from the extracellular to the intracellular space. Tyrosine receptor kinases are proteins located on the surface of the cell membrane and passing through the whole thickness of it. Tyrosine non-receptor kinases transfer the signal within the cell [17]. The mTOR protein is a cytoplasmic serine/threonine kinase. It is a component of the intracellular pathway PI3/Akt/mTOR, which is responsible for cellular growth regulation and metabolism.

The mitogen-activated protein kinase (MAPK) pathway is a factor mediating signal transfer between the extraand intracellular space.

This pathway includes RAS, RAF, and MEK proteins. The RAF protein is a group of three serine/threonine kinases: A-RAF, B-RAF, and C-RAF (RAF-1). It is believed that mutations in B-RAF occur in about $70 \%$ of melanomas, but they are present in colorectal and ovarian cancer as well [15].

Bevacizumab is a humanized recombined monoclonal antibody belonging to the IgG group. It is aimed against vascular endothelial growth factor (VEGF) [18, 19]. Significant hepatotoxicity from using bevacizumab has not been observed. Toxic injury of hepatocytes that occurs during the treatment is associated with the use of cytostatic agents at the same time. However, there are publications that discuss the protective action of bevacizumab in conjunction with chemotherapy. It is believed that it can protect against liver sinusoid damage [20].

Rituximab is a chimerical monoclonal class IgG1 antibody directed against membrane antigen CD20 which is present on $B$ lymphocytes. There is a lack of information in the literature about hepatotoxic action of this drug (Table 2).

Ipilimumab is a human monoclonal IgG antibody. Its mechanism consists in blocking antigen 4 (CTLA-4), associated with cytotoxic T lymphocyte. CTLA-4 takes part in suppression of the pathway that stimulates T lymphocytes (Table 2). The third phase trials with a triple blind study concluded that as a result of using ipilimumab as monotherapy in 131 patients, there was an increase of ASPAT in 1 patient and an increase of ALAT in 2 patients. Hepatitis occurred in 1 patient. None of the mentioned undesirable effects indicated the third or fourth stage of toxicity [21].

Trastuzumab is a humanized monoclonal antibody belonging to the IgG1 class. It affects epidermal growth factor receptor HER-2 (Table 2). The indication to treat is when expression of the HER2 receptor is observed in the histopathologic specimen of breast or stomach cancer. In the literature, there is one report concerning drug-induced liver damage associated with use of trastuzumab. The case concerned a 54-year-old African American woman who 
Table 2. Hepatotoxicity of molecular targeted therapy

\begin{tabular}{|c|c|c|c|c|}
\hline \multicolumn{2}{|c|}{ Molecular targeted therapy } & \multirow{2}{*}{$\begin{array}{l}\text { Aim } \\
\text { VEGF }\end{array}$} & \multirow{2}{*}{$\begin{array}{l}\text { Registration indications [18] } \\
\text { colon cancer, rectum cancer, breast cancer, non-small- } \\
\text { cell lung cancer, ovarian epithelial cancer }\end{array}$} & \multirow{2}{*}{$\begin{array}{l}\text { Hepatotoxicity } \\
-\end{array}$} \\
\hline \multirow{6}{*}{$\begin{array}{l}\text { Monoclonal } \\
\text { antibodies }\end{array}$} & bevacizumab & & & \\
\hline & rituximab & membrane antigen CD 20 & follicular lymphoma, diffuse large B-cell lymphoma & - \\
\hline & ipilimumab & CTLA-4 & malignant melanoma & + \\
\hline & trastuzumab & HER 2 & breast cancer, stomach cancer & + \\
\hline & cetuximab & EGFR & $\begin{array}{l}\text { colon and rectum cancer, head and neck squamous } \\
\text { cell carcinoma }\end{array}$ & - \\
\hline & panitumumab & EGFR & colon and rectum cancer & - \\
\hline \multirow{9}{*}{ Kinase inhibitors } & erlotinib & EGFR & non-small-cell lung cancer, pancreatic cancer & + \\
\hline & gefitinib & EGFR & non-small-cell lung cancer & + \\
\hline & lapatinib & EGFR, HER 2 & breast cancer & +++ \\
\hline & sorafenib & $\begin{array}{l}\text { RAF, VEGFR type } 1,2 \text { and } \\
\text { 3, PDGFR, c-KIT }\end{array}$ & hepatocellular carcinoma, kidney cancer & ++ \\
\hline & pazopanib & $\begin{array}{l}\text { PDGFR, c-KIT, VEGFR type } \\
1 \text { and } 2\end{array}$ & $\begin{array}{l}\text { renal cell carcinoma, some forms of soft tissue } \\
\text { sarcoma }\end{array}$ & +++ \\
\hline & sunitinib & $\begin{array}{l}\text { VEGFR type } 1 \text { and 2, } \\
\text { PDGFR, C-KIT, FLT-3, RET }\end{array}$ & $\begin{array}{l}\text { gastrointestinal stromal tumors, renal cell carcinoma, } \\
\text { neuroendocrine pancreatic tumors }\end{array}$ & +++ \\
\hline & imatinib & BCR-ABL, KIT, PDGFR & $\begin{array}{l}\text { chronic myeloid leukemia, acute lymphoblastic } \\
\text { leukemia, in myelodysplastic or myeloproliferative } \\
\text { disease, gastrointestinal stromal tumors, skin nodular } \\
\text { fibrosarcoma }\end{array}$ & ++ \\
\hline & temsirolimus & mTOR & renal cell carcinoma, mantle cell lymphoma & - \\
\hline & everolimus & mTOR & $\begin{array}{l}\text { breast cancer, pancreatic neuroendocrine tumors, } \\
\text { renal cell carcinoma }\end{array}$ & - \\
\hline $\begin{array}{l}\text { Proteasome } \\
\text { inhibitor }\end{array}$ & bortezomib & UP-S & multiple myeloma & + \\
\hline $\begin{array}{l}+: \text { single cases of } \\
++: \text { hepatotoxicity } \\
+++ \text { hepatotoxici } \\
\text {-: lack of informa }\end{array}$ & $\begin{array}{l}\text { epatotoxicity diagr } \\
\text { occurs } \\
\text { of } 2^{\text {nd }} \text { and } 3^{\text {rd }} \text { degr } \\
\text { on concerning hep }\end{array}$ & & & \\
\hline
\end{tabular}

was suffering from advanced locally invasive breast cancer. As a result of using trastuzumab, an increase of ASPAT, ALAT and alkaline phosphatase activity followed. After discontinuing this drug, these values returned to normal [22].

Cetuximab is an IgG1 chimerical antibody, made by DNA recombination of mammalian cell lines. Panitumumab, on the other hand, is a monoclonal human IgG2 antibody. The conditions necessary to treat with cetuximab or panitumumab are proof of EGFR expression in tumor cells as well as the lack of KRAS gene mutation (Table 2) [18]. In the literature, there is a lack of information confirming liver injury of the third and fourth stage as a result of using cetuximab or panitumumab as monotherapy. In the case of treating with cetuximab or panitumumab in association with chemotherapy, hepatocyte damage can occur, but it is a result of the cytostatic action.
Erlotinib is an intracellular tyrosine kinase inhibitor of endothelial growth factor receptor (Table 2). It is mainly metabolized by cytochrome P450 3A4, and to a lesser degree by cytochrome P450 1A2. A 50\% decrease in dosing is recommended when ASPAT activity is elevated by more than three times the upper limit of the normal range, or the bilirubin level increases to $17-120 \mu \mathrm{mol} / \mathrm{l}$ [23]. No significant disorders in liver function have been noted due to using erlotinib as monotherapy [24]. However, in a third phase trial which evaluated the effectiveness of erlotinib in conjunction with gemcitabine in comparison to gemcitabine monotherapy in patients with locally advanced or disseminated pancreatic cancer, an increase of ASPAT consistent with third degree liver damage was observed in $11 \%$ of patients receiving erlotinib compared to $8 \%$ of patients in the other group [25]. 
The group of tyrosine kinase inhibitors of EGFR also includes gefitinib (Table 2). Gefitinib rarely causes an aminotransferase increase. It has been proven that second and third stage liver damage occurred in $6.7 \%$ of patients who were treated with gefitinib, according to the WHO [26]. There are some reports which say that following gefitinib which evoked hepatotoxicity with erlotinib may cause a decrease in serum liver enzyme values and bring clinical benefit during the treatment of neoplastic disease [27].

Lapatinib is an intracellular tyrosine kinase domain inhibitor bound with erbB1 and ErbB-2 receptors (Table 2) [17]. It can cause an increase of ASPAT and ALAT to more than three times higher than normal and increase bilirubin to more than twice as high as normal. This hepatotoxicity is probably a result of the metabolism and distribution of the drug [28]. Lapatinib belongs to the group of CYP3A4 inhibitors. The mechanism of liver damage may proceed idiosyncratically [29].

Sorafenib belongs to the group of B-RAF and C-RAF serine/tyrosine kinase inhibitors. It is, additionally, an inhibitor of vascular endothelial growth factor receptor (VEGFR) and platelet-derived growth factor receptor (PDGFR) (Table 2) [15]. Its action can affect many tyrosine kinases. It is metabolized by cytochrome P450 3A4 in the liver [23]. There are many publications which report toxic drug-induced liver damage caused by sorafenib [30]. In case of an increase in bilirubin or decrease of albumin values it is recommended to reduce the drug dose [23].

Pazopanib belongs to the group of angiogenesis inhibitors. It works against platelet-derived growth factor receptor, vascular endothelial growth factor receptor and c-Kit (Table 2). The randomized third phase double blind trial VEG105192 evaluated efficacy and safety when using pazopanib in patients with advanced localized or disseminated renal clear cell carcinoma. Based on laboratory tests, the most often occurring side effects were increased serum values of ALAT and ASPAT. The increase in ALAT activity was three times higher than the upper limit of normal in $18 \%$ of patients who took the drug. A decrease in the toxicity degree after reducing the drug dose occurred in $87 \%$ of patients. Twenty-five patients experienced the fourth degree of drug toxicity. Fifty-three percent of patients who were treated with pazopanib were diagnosed with increased ASPAT; however, the fourth degree of toxicity occurred in less than $1 \%$ of cases. An increase of bilirubin value in serum was noted in $36 \%$ of people treated with pazopanib; however, that complication in the fourth degree of toxicity occurred in less than $1 \%$ of patients. Clot complications occurred in about $3 \%$ of patients [31].

Sunitinib is an inhibitor of not only tyrosine kinase, but also of VEGFR type 1 and 2, PDGFR and c-KIT receptors, FLT-3 and RET kinase (Table 2). It is a very strong inhibitor of CYP3A4 as well [32]. As a result of using sunitinib, liver damage in the fourth degree of toxicity can occur [33].

Imatinib belongs to the group of tyrosine kinase inhibitors and its aim is to suppress BCR-ABL kinase. It suppresses KIT kinase and growth factor receptor as well (Table 1). It was realized that it can cause liver damage along with necrosis. Hepatocyte damage was confirmed in about 10\% of patients, out of which 2-6\% sustained damage of the fourth degree [4].

The group of mTOR protein inhibitors (cytoplasmic serine-tyrosine kinase) includes temsirolimus and everolimus (Table 2). In the literature, there is no information about toxicity of these substances.

The ubiquitin-proteasome system (U-PS) is responsible for regulation of the cell cycle, DNA repair and degradation of suppressing and proapoptotic proteins. It has been proven that inactivation of the proteasome stimulates apotheosis, suppresses proliferation and intensifies the effects of radiation therapy and chemotherapy. Bortezomib, as an inhibitor of proteasome, induces apoptosis and blocks the proliferation of plasmacytoid cells [15]. While treating with bortezomib, mild liver damage can occur. However, cases of acute liver damage have been reported.

\section{Summary}

While analyzing data on toxicity of individual molecularly targeted drugs, it was noted that there were increases of serum ASPAT and ALAT values in less than 10\% of patients treated with sunitinib and sorafenib, while the increases were present in more than $10 \%$ of patients treated with pazopanib and mTOR inhibitors. Hyperbilirubinemia was diagnosed in over $10 \%$ of patients treated with sunitinib, pazopanib, and everolimus. Pazopanib causes an increase of serum ALAT level in 14\% and hyperbilirubinemia in $3 \%$ of patients. As an adverse result of treating with pazopanib, cases of liver damage ending up with patients' death were observed. For this reason the Food and Drug Administration (FDA) ordered the inclusion of additional, so-called "black box warnings" concerning elevated risk of liver damage due to the treatment with pazopanib. Similar warnings apply to sunitinib and lapatinib. In March 2013 in the USA the multikinase inhibitor regorafenib was registered. Its use is linked to significant hepatotoxicity; hence it is labeled with the "black box warning". In 2013 a meta-analysis was published; it evaluated the range of hepatotoxicity appearing during treatment with tyrosine kinases. The analysis included substances which the FDA registered between January 1995 and June 2012. Inclusion criteria were the presence of control support with placebo as well as occurrence during the research of undesirable effects in the form of liver damage according to Common Terminology Criteria for Adverse Events (CTCAE), version 2.0 and 3.0. Twelve randomized double blind clinical trials, attempting to assess the effectiveness of tyrosine kinase inhibitors in neoplasm treatment, were analyzed; 5 of them were phase II, the rest of them phase III. The research was divided into two categories; the first one concerned determining the effectiveness of a tyrosine kinase inhibitor versus placebo. The second category concerned determining the effectiveness of a tyrosine kinase inhibitor in conjunction with chemotherapy, compared to chemotherapy alone, versus placebo. All in all, 3104 patients' treatments were analyzed, out of which the largest group (682 patients) was taking part in the trial concerning GIST imatinib treatment, which was published in 2009 by De Matteo and partners. The above-mentioned meta-analysis 
proved at least a twofold increase in the risk of hepatotoxicity occurring among patients who take tyrosine kinase inhibitors. Liver damage appeared as ASPAT and ALAT levels increased; however, an increase of bilirubin level in serum was not noted. This may suggest that the liver damage resulting from tyrosine kinase inhibitors is related mainly to the hepatocyte damage and not the cholestatic damage. It is quite interesting that tyrosine kinase inhibitors bound with EGFR are probably less hepatotoxic than tyrosine kinase inhibitors not bound with EGFR. However, these data are not statistically significant [16].

\section{The authors declare no conflict of interest.}

\section{References}

1. Zatoński W, Tyczyński J. Nowotwory złośliwe w Polsce w 1990 roku. Biuletyn PDF. http://www.onkologia.org.pl/doc/90.pdf.

2. Raporty na podstawie danych Centrum Onkologii. http://epid.coi. waw.pl/krn/

3. Piątkowska M, Pogorzała M, Dębski R, Styczyński J. Hepatotoksyczność w przebiegu chemioterapii przeciwnowotworowej. Wspolczesna Onkol 2008; 12: 16-9.

4. Field K, Dow C, Michael M. Part I: Liver function in oncology: biochemistry and beyond. Lancet Oncol 2008; 9: 1092-101.

5. Stine J, Sateesh P, Lewis J. Drug-induced liver injury in the elderly. Curr Gastroenterol Rep 2013; 15: 299.

6. Navarro V, Senior J. Drug-related hepatotoxicity. N Engl J Med 2006; 354: 731-9.

7. Szczeklik A. Choroby wewnetrzne - stan wiedzy na rok 2011. Medycyna Praktyczna. Kraków 2011.

8. Superfin D, Iannucci A, Davies A. Commentary: Oncologic drugs in patients with organ dysfunction: a summary. Oncologist 2007; 12: 1070-83.

9. Szelag A, Merwid-Ląd A, Trocha M, Skrzypiec M, Smereka A. Patomechanizmy hepatotoksycznego działania leków. Gastroenterol Pol 2003; 10; 425-9.

10. Hartleb M. Polekowe uszkodzenia wątroby. Terapia 2008; 6: 67-74.

11. Bibi Z. Role of cytochrome P450 in drug interactions. Nutr Metab (Lond) 2008; 5: 27.

12. Gunawan B, Kaplowitz N. Clinical perspectives on xenobiotic-induced hepatotoxicity. Drug Metab Rev 2004; 36: 301-12.

13. Benichou C. Criteria of drug-induced liver disorders. Report of an International Consensus Meeting. J Hepatol 1990; 11: 272-6.

14. Topalian S, Weiner G, Pardoll D. Cancer immunotherapy comes of age. J Clin Oncol 2011; 29: 4828-36.

15. Wen W, Adjei A. Novel agents on the horizon for cancer therapy. Ca Cancer J Clin 2009; 59: 111-37.

16. Teo Y, Ho H, Chan A. Risk of tyrosine kinase inhibitors- induces hepatotoxicyty In cancer patients: A meta-analysis. Cancer Treat Rev 2013; 39: 199-206.

17. Mukherjee A, Dhadda A, Shehata M, Chan S. Lapatinib: a tyrosine kinase inhibitor with a clinical role in breast cancer. Expert Opin Pharmacother 2007; 8: 2189-204.

18. European Medicines Agency. http://www.ema.europa.eu/ema/

19. Frampton J, Keating G. Bevacizumab: in first-line treatment of advanced and/or metastatic renal cell carcinoma. BioDrugs 2008; 22: 113-20.

20. Zalinski S, Bigourdan J, Vauthey J. Does bevacizumab have a protective effect on hepatotoxicity induced by chemotherapy? J Chir 2010; 47 Supp 1: 18-24

21. Hodi F, O'Day S, McDermott D, et al. Improved survival with ipilimumab in patients with metastatic melanoma. N Engl J Med 2010 363: 711-23.

22. Srinivasan S, Parsa V, Liu C, Fontana J. Trastuzumab-induced hepatotoxicity. Ann Pharmacother 2008; 42:1497-501.

23. Field K, Michael M. Part II: Liver function in oncology: towards safer chemotherapy use. Lancet Oncol 2008; 9: 1181-90.
24. Shepherd F, Rodrigues Pereira J, Ciuleanu T, et al. National Cancer Institute of Canada Clinical Trials Group. Erlotinib in previously treated non-small-cell lung cancer. N Engl J Med 2005; 353: 123 32.

25. Moore M, Goldstein D, Hamm J, et al. Erlotinib plus gemcitabine compared with gemcitabine alone in patients with advanced pancreatic cancer: a phase III trial of the National Cancer Institute of Canada Clinical Trials Group. J Clin Oncol 2007; 25: 1960-6.

26. Yin YM, Geng YT, Shao YF, Hu XL, Li W, Shu YQ, Wang ZX. First-line single agent treatment with gefitinib in patients with advanced non-small-cell lung cancer. J Exp Clin Cancer Res 2010; 29: 126.

27. Kitade H, Yamada T, Igarashi S, et al. Efficacy of low-dose erlotinib against gefitinib-induced hepatotoxicity in a patient with lung adenocarcinoma harboring EGFR mutations. Gan To Kagaku Ryoho 2013; 40: 79-81.

28. Castellino S, O'Mara M, Koch K, Borts DJ, Bowers GD, MacLauchlin C. Human metabolism of lapatinib, a dual kinase inhibitor: implications for hepatotoxicity. Drug Metab Dispos 2012; 40: 139-50.

29. Teng WC, Oh JW, New LS, Wahlin MD, Nelson SD, Ho HK, Chan EC. Mechanism-based inactivation of cytochrome P450 3A4 by lapatinib. Mol Pharmacol 2010; 78: 693-703.

30. Fairfax B, Pratap S, Roberts I, et al. Fatal case of sorafenib-associated idiosyncratic hepatotoxicity in the adjuvant treatment of a patient with renal cell carcinoma. BMC Cancer 2012; 12: 590.

31. Sternberg C, Davis I, Mardiak J, Szczylik C, et al. Pazopanib in locally advanced or metastatic renal cell carcinoma: results of a randomized phase III trial. J Clin Oncol 2010; 28: 1061-8.

32. Hutson T, Figlin R, Kuhn J, Motzer R. Targeted therapies for metastatic renal cell carcinoma: an overview of toxicity and dosing strategies. Oncologist 2008; 13: 1084-96.

33. Mueller E, Rockey M, Rashkin M. Sunitinib-related fulminant hepatic failure: case report and review of the literature. Pharmacotherapy 2008; 28: 1066-70.

\section{Address for correspondence}

\section{Bożenna Karczmarek-Borowska}

Department of Oncology

Faculty of Medicine

University of Rzeszow

Chopina 2

35-105 Rzeszów, Poland

e-mail: bkb8@tlen.pl

Submitted: 27.10.2013

Accepted: $\quad 26.03 .2014$ 